\title{
AN EXPERIMENT ON THE EFFECT OF INHALATION OF ETHYLENE.
}

\author{
By J. LORRAIN SMITH, M.A., M.D., \\ AND A. PERCY HOSKINS, F.C.S., F.I.C.
}

\section{(From the Pathological Laboratory, Queen's College, Belfast.)}

THE opinion has recently been expressed ${ }^{1}$ that the poisonous action of ordinary coal-gas and carburetted water-gas is probably in part due to the "Illuminant" hydro-carbons, of which ethylene is the chief, and not simply to carbonic oxide. In consequence of the doubt existing on this point one of us was asked by the recent Departmental Committee of the Home Office on Water-Gas to investigate the matter, and the results of the experiments which we were then able to make appeared in the Committee's Reporty. In the main series of observations the animal was placed in a respiration chamber through which a current of air was passing at a known rate. With the current, before it entered the chamber, a known percentage of coal-gas or carburetted water-gas was mixed. It was found that whether ordinary coal-gas or carburetted water-gas was used the symptoms observed were those of carbonic oxide poisoning, and corresponded exactly to the percentages of carbonic oxide present. We also found that Benzene, which is one of the "illuminants," is present in proportions far too small to contribute to the toxic effects of coal-gas or carburetted water-gas. Finally, we endeavoured to investigate separately the action of ethylene. The ethylene we then used was prepared in the ordinary way from sulphuric acid and alcohol, and when about $10 \%$ of the gas was mixed with air and supplied to an animal very distinct toxic symptoms were produced.

1 See Sir Henry Roscoe's evidence, Appendix to the Report of the Water-Gas Committee (Parliamentary Paper), p. 109, 1899.

2 Appendix, p. 127. 


\section{Experiment on the Effect of Inhalation of Ethylene}

On shaking the ethylene with blood solution we found, however, that carbonic oxide was present; and a determination of the latter by the blood method ${ }^{1}$ gave $1.8 \%$. The carbonic oxide present was thus sufficient to account for the symptoms observed.

The experiment now to be described was made with ethylene prepared from ethylene dibromide by the action of a zinc-copper couple $^{2}$. The sample of gas obtained was found, when tested with blood solution, to be free from carbonic oxide, and gave, on analysis, the following result:

$\begin{array}{lr}\text { Ethylene } & 96.0 \\ \text { Oxygen } & 0.5 \\ \text { Nitrogen } & 1.7 \\ \text { Hydrogen } & \mathbf{1} \cdot 4 \\ \text { Ethane } & \mathbf{0 . 4} \\ & \underline{100 \cdot 0}\end{array}$

We filled a cylinder of 1100 c.c. capacity with a mixture of $72.5 \%$ of the ethylene and $27.5 \%$ of oxygen. After thorough mixture of the gas a mouse was placed in the cylinder. At the end of a minute the mouse seemed to have some difficulty in walking, as if slight intoxication had resulted from breathing the ethylene. Careful observation was continued for an hour, but the symptoms did not become in any way more marked. The mouse was then taken from the cylinder, and ran along the floor at once and with perfect ease.

From this experiment it is evident that the effects produced by ethylene are very slight, even when $72 \%$ of the gas is present. Ordinary coal-gas does not contain more than 3 or $4 \%$ of ethylene, and in air which has been rendered just poisonous by the addition of coal-gas only about $0.2 \%$ of ethylene would be present, so that it is impossible to attribute to ethylene any part of the poisonous action of coal-gas.

1 Haldane, (1898) Journal of Physiol., vol. 22, p. 478.

2 Roscoe and Schorlemmer's Chemistry, Vol. nI. pt. 2, p. 37 (1890). 